\title{
Direct Catalytic Enantio- and Diastereoselective Ketone Aldol Reactions of Isocyanoacetates**
}

\author{
Raquel de la Campa, Irene Ortín, and Darren J. Dixon*
}

\begin{abstract}
A catalytic asymmetric aldol addition/cyclization reaction of unactivated ketones with isocyanoacetate pronucleophiles has been developed. A quinine-derived aminophosphine precatalyst and silver oxide were found to be an effective binary catalyst system and promoted the reaction to afford chiral oxazolines possessing a fully substituted stereocenter with good diastereoselectivities and excellent enantioselectivities.
\end{abstract}

$T_{\text {he aldol reaction is one of the most powerful methods for }}$ the construction of $\beta$-hydroxy carbonyl compounds. ${ }^{[1]}$ The importance of these building blocks, contained in a wide variety of biologically relevant compounds, has promoted the development of several catalytic asymmetric methods for their production. ${ }^{[2]}$ However, despite enormous progress in the aldol addition arena, its application to the synthesis of tertiary alcohols still remains a major challenge, principally owing to a lack of reactivity and the fact that the differentiation of the enantiotopic faces is more difficult with ketone electrophiles than with the corresponding aldehydes. Furthermore, deleterious side reactions, such as retro-aldol reactions, can predominate when a ketone moiety is involved. ${ }^{[3]}$ Although a few catalytic asymmetric aldol reactions with unactivated ketones have been reported, ${ }^{[4]}$ the development of new and efficient catalytic asymmetric methods to access chiral tertiary alcohols remains an important goal in modern asymmetric catalysis. ${ }^{[5]}$

Along these lines, we recognized that the catalytic asymmetric ketone aldol reaction of isocyanoacetate pronucleophiles $^{[6]}$ could be a synthetically powerful approach.

[*] Dr. R. de la Campa, Dr. I. Ortín, Prof. Dr. D. J. Dixon Department of Chemistry, Chemistry Research Laboratory University of Oxford

Mansfield Road, Oxford OX1 3TA (UK)

E-mail: darren.dixon@chem.ox.ac.uk

[*** We thank the EPSRC (Leadership Fellowship to D.J.D.), the EC [IEF to R.C. (PIEF-CA-2012-329689) and IEF to I.O. (PIEF-CA-2010275788)] for funding, Allegra Franchino of the Department of Chemistry, University of Oxford for the preparation of precatalyst 1 b, Pablo García of the Department of Chemistry, University of Oviedo and Matt Rattley and Yinchao Yang of the Department of Chemistry, University of Oxford for X-ray analysis, and the Oxford Chemical Crystallography Service for use of their instrumentation. Supporting information for this article is available on the WWWW under http://dx.doi.org/10.1002/anie.201411852.

of (c) 2015 The Authors. Published by Wiley-VCH Verlag GmbH \& Co. $\mathrm{KGaA}$. This is an open access article under the terms of the Creative Commons Attribution License, which permits use, distribution and reproduction in any medium, provided the original work is properly cited.
Isocyanoacetate ester addition reactions to carbony $\mathrm{l}^{[7]}$ or imine electrophiles ${ }^{[8,9]}$ directly afford the respective oxazoline or imidazoline heterocycles, which can be ring-opened under mild hydrolytic conditions to yield $\beta$-substituted $\alpha$-amino acids. Although the catalytic asymmetric version of this reaction has been widely studied using aldehydes ${ }^{[7]}$ to date, no enantioselective example using unactivated ketones has been reported despite its potential to provide an elegant asymmetric route to $\alpha$-amino acid derivatives possessing a chiral tertiary alcohol in the $\beta$-position (Scheme 1 ) ${ }^{[10]}$ In

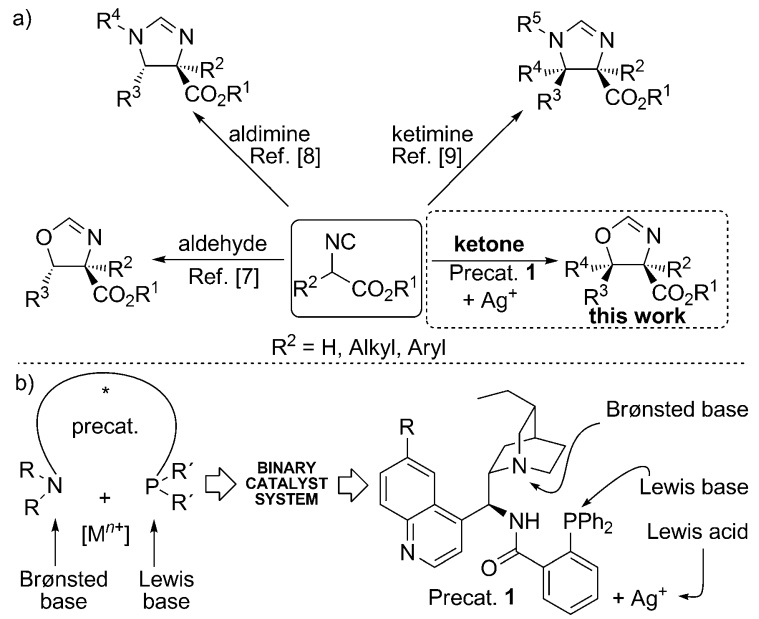

Scheme 1. a) Catalytic asymmetric addition reactions of isocyanoacetate pronucleophiles to carbonyl or imine electrophiles. b) Aminophosphine/silver(I) binary catalyst system applied in this work.

a related study, the asymmetric aldol addition reaction of isothiocyanato esters and unactivated ketones, which afforded oxazolidinethione products with a fully substituted $\beta$-stereocenter, was described. ${ }^{[11]}$

For promoting and controlling various addition reactions, our group has developed an effective binary catalyst system comprising a "soft" metal ion, such as a silver (I) ion, and a cinchona-derived aminophosphine precatalyst of type $\mathbf{1}$. This system promotes the highly diastereo- and enantioselective aldol reaction of isocyanoacetates with aldehydes ${ }^{[71]}$ and Mannich reactions of aldimines ${ }^{[8 \mathrm{e}]}$ and ketimines. ${ }^{[\mathrm{a}]}$ The precatalyst is equipped with Brønsted basic and Lewis basic sites and also possesses a hydrogen-bond donor group located in the proximity of the chiral pocket that is created by the cinchona scaffold (Scheme 1). In conjunction with $\mathrm{Ag}^{\mathrm{I}}$ ions, these features provide remarkable catalytic activity in reactions of isocyanoacetate pronucleophiles and accordingly prompted us to address the challenging enantioselective aldol reaction of unactivated ketones. 
Initially, the reaction of acetophenone (3a) and tert-butyl isocyanoacetate $(\mathbf{2 a})$ in EtOAc at $-20^{\circ} \mathrm{C}$ was selected as a model system, and the performance of our previously described silver oxide/aminophosphine catalytic system, which was employed in a 2:1 molar ratio of aminophosphine precatalyst to metal, was assessed. ${ }^{[71]}$ Pleasingly, using cinchonidine-derived aminophosphine 1c, trans-oxazoline $(4 R, 5 S)$ 4a was obtained as the major product with significant diastereo- and enantiocontrol (Table 1, entry 1; 89:11 d.r.,

Table 1: Optimization studies.

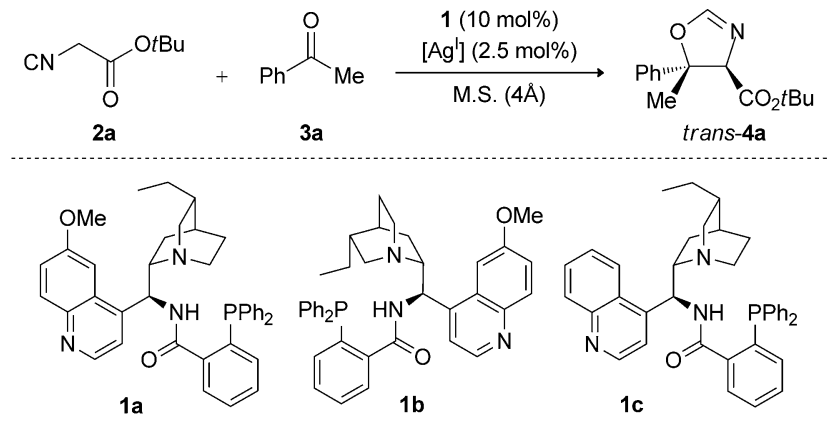

\begin{tabular}{|c|c|c|c|c|c|c|c|c|}
\hline Entry & 1 & {$[\mathrm{Ag}]$} & $T\left[{ }^{\circ} \mathrm{C}\right]$ & Solvent & $t[\mathrm{~h}]$ & Yield $^{[\mathrm{a}]}[\%]$ & d.r. ${ }^{[b]}$ & e.r. ${ }^{[c]}$ \\
\hline 1 & $1 c$ & $\mathrm{Ag}_{2} \mathrm{O}$ & -20 & EtOAc & 60 & 78 & $89: 11$ & $90: 10$ \\
\hline 2 & $1 \mathrm{a}$ & $\mathrm{Ag}_{2} \mathrm{O}$ & -20 & EtOAc & 60 & 93 & $95: 5$ & $94: 6$ \\
\hline 3 & $1 \mathrm{~b}$ & $\mathrm{Ag}_{2} \mathrm{O}$ & -20 & EtOAc & 60 & 82 & $90: 10$ & $90: 10^{[d]}$ \\
\hline 4 & $1 \mathrm{a}$ & $\mathrm{Ag}_{2} \mathrm{CO}_{3}$ & -20 & EtOAc & 24 & 64 & $91: 9$ & $94: 6$ \\
\hline 5 & $1 \mathrm{a}$ & $\mathrm{AgOAc}$ & -20 & EtOAc & 48 & 55 & $88: 12$ & $91: 9$ \\
\hline 6 & $1 \mathrm{a}$ & $\mathrm{Ag}_{2} \mathrm{O}$ & -20 & TBME & 36 & 74 & $88: 12$ & $94: 6$ \\
\hline 7 & $1 \mathrm{a}$ & $\mathrm{Ag}_{2} \mathrm{O}$ & -20 & $\mathrm{CH}_{2} \mathrm{Cl}_{2}$ & 36 & 63 & $79: 12$ & $85: 15$ \\
\hline 8 & $1 \mathrm{a}$ & $\mathrm{Ag}_{2} \mathrm{O}$ & -20 & iPrOAc & 36 & 79 & $89: 11$ & $93: 7$ \\
\hline 9 & $1 \mathrm{a}$ & $\mathrm{Ag}_{2} \mathrm{O}$ & -30 & EtOAc & 96 & 84 & $90: 10$ & $94: 6$ \\
\hline 10 & $1 \mathrm{a}$ & $\mathrm{Ag}_{2} \mathrm{O}$ & 0 & EtOAc & 48 & 84 & $89: 11$ & $92: 8$ \\
\hline 11 & $1 \mathrm{a}$ & - & -20 & EtOAc & 120 & 0 & - & - \\
\hline 12 & - & $\mathrm{Ag}_{2} \mathrm{O}$ & -20 & EtOAc & 120 & 0 & - & - \\
\hline
\end{tabular}

[a] Combined yield of both diastereomers after flash column chromatography. [b] The diastereomeric ratio (d.r.) is given as the trans/cis ratio and was determined by ${ }^{1} \mathrm{H}$ NMR analysis of the crude reaction mixture. [c] The enantiomeric ratios (e.r.) were determined by HPLC analysis on a chiral stationary phase. [d] Enantiomeric (4S,5R)-4a was obtained. M.S. $=$ molecular sieves, TMBE $=$ tert-butyl methyl ether.

90:10 e.r.). With quinine-derived precatalyst $\mathbf{1 a}$, product $\mathbf{4 a}$ was afforded in higher diastereo- and enantioselectivity (entry 2; 95:5 d.r., 94:6 e.r.), whereas pseudoenantiomeric 1b yielded the enantiomeric product $(4 S, 5 R)-\mathbf{4 a}$ as a $90: 10$ mixture of diastereomers with 90:10 e.r. (entry 3). Alternative silver sources were also tested in conjunction with precatalyst 1a (entries 4 and 5) in the hope that an increase in the selectivity would be observed. Although the use of silver carbonate afforded trans-oxazoline product $(4 R, 5 S)$-4a with high enantioselectivity (entry 4; 91:9 d.r., 94:6 e.r.), 4a was formed with enhanced diastereocontrol and yield when silver(I) oxide was employed (see entry 2). In terms of diastereoselectivity, EtOAc was found to be the best solvent compared with TBME, $\mathrm{CH}_{2} \mathrm{Cl}_{2}$, or $i$ PrOAc (entries 2 and $6-$ 8). Changing the temperature of the reaction to $-30^{\circ} \mathrm{C}$ or to $0{ }^{\circ} \mathrm{C}$ from $-20^{\circ} \mathrm{C}$ made no improvement to the enantioselectivity (entries 9 and 10). Finally, reactions performed in the absence of $\mathrm{Ag}_{2} \mathrm{O}$ or without precatalyst $\mathbf{1}$ a gave no product after five days at $-20^{\circ} \mathrm{C}$ (entries 11 and 12). These results demonstrate that the active catalyst is made from a combination of aminophosphine precatalyst $\mathbf{1 a}$ and $\mathrm{a}^{\mathrm{Ag}}$ salt.

Subsequently, the effect of lowering the catalyst loading was studied (Table 2). trans-Oxazoline 4 a was obtained with marginally lower levels of enantioselectivity when the loading was reduced to 5 and $1 \mathrm{~mol} \%$ of $\mathbf{1 a}$ while maintaining

Table 2: Variations of the catalyst loading.

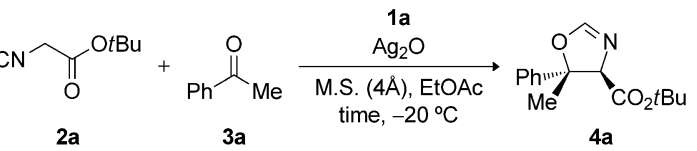

\begin{tabular}{lllllll}
\hline Entry & $\mathrm{1a}(\mathrm{mol} \%)$ & $\mathrm{Ag}_{2} \mathrm{O}(\mathrm{mol} \%)$ & $t[\mathrm{~h}]$ & Yield $^{[\mathrm{a}]}[\%]$ & d.r. $^{[\mathrm{b}]}$ & e.r. $^{[\mathrm{c}]}$ \\
\hline 1 & 5 & 2.5 & 72 & 84 & $94: 6$ & $94: 6$ \\
2 & 5 & 1.25 & 96 & 85 & $90: 10$ & $93: 7$ \\
3 & 1 & 0.25 & 96 & 73 & $86: 14$ & $90: 10$
\end{tabular}

[a] Combined yield of both diastereomers after flash column chromatography. [b] Given as the trans/cis ratios and determined by ${ }^{1} \mathrm{H}$ NMR analysis of the crude reaction mixture. [c] Determined by HPLC analysis on a chiral stationary phase.

a precatalyst/metal ratio of 2:1 ratio (entries 2 and 3). However, diastereo- and enantioselectivities that are comparable to the best values reported in Table 1 were achieved when precatalyst $\mathbf{1 a}$ and $\mathrm{Ag}^{\mathrm{I}}$ were employed in a 1:1 ratio at a precatalyst loading of $5 \mathrm{~mol} \%$ (entry 1 ).

With the optimized conditions established, we proceeded to study the scope of the reaction of tert-butyl isocyanoacetate (2a) with different alkyl aryl ketones in the presence of quinine-derived aminophosphine precatalyst $\mathbf{1 a}$ and $\mathrm{Ag}_{2} \mathrm{O}$ (Table 3). Several substituted methyl aryl ketones with either electron-withdrawing or -donating groups afforded the transconfigured oxazolines $\mathbf{4 b - 4 f}$ as the major products with good diastereoselectivities and very good enantioselectivities (Table 3, entries 2-6; 93:7-96:4 e.r.). Pleasingly, methyl ketone substrates $\mathbf{3 i}$ and $\mathbf{3 j}$, which feature five- and sixmembered heteroaromatic rings, were also well tolerated giving products $\mathbf{4 i}$ and $\mathbf{4 j}$ with good stereoselectivities (entries 9 and 10). An important success was observed when aryl ethyl ketones $\mathbf{3 k} \mathbf{k}-\mathbf{3 n}$ were used in the reaction. transOxazolines $4 \mathbf{k}-\mathbf{4 n}$ were obtained as the major products with good diastereoselectivities and excellent enantioselectivities (entries 11-14; 98:2-99:1 e.r.). Aryl propyl ketones 3o-3p were also excellent substrates and afforded the trans-configured oxazoline products $\mathbf{4 o - 4} \mathbf{p}$ in high yields and in good to excellent enantioselectivities (entries 15 and 16). Finally, isovalerophenone $\mathbf{3 q}$ afforded trans-oxazoline $\mathbf{4 q}$ in $75 \%$ yield, 96:4 d.r., and 97:3 e.r. (entry 17), demonstrating the broad scope of the reaction with respect to different nonactivated ketones. We also studied the scope of the reaction with different isocyanoacetates (entries 18-20). With ethyl isocyanoacetate $(\mathbf{2 b})$ or methyl isocyanoacetate $(\mathbf{2 c})$, the trans-configured oxazoline products $\mathbf{4 r}-\mathbf{4 t}$ were obtained with very good diastereoselectivities and excellent enantioselectivities. Unfortunately, under the optimized conditions, symmetric and unsymmetric aliphatic ketones afforded the corresponding oxazoline products with poor enantioselectivities. $^{[12]}$ 
Table 3: Scope of the ketone aldol/cyclization reaction with isocyanoacetates.

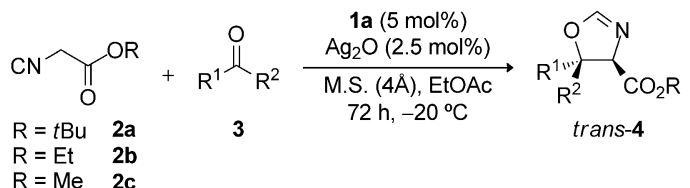

\begin{tabular}{|c|c|c|c|c|c|c|c|c|}
\hline Entry & 2 & 3 & $\mathrm{R}^{1}$ & $\mathrm{R}^{2}$ & 4 & Yield [\%] ${ }^{[\mathrm{a}]}$ & d.r..$^{[b]}$ & e.r. ${ }^{[c]}$ \\
\hline 1 & $2 a$ & $3 a$ & $\mathrm{Ph}$ & $\mathrm{Me}$ & $4 a$ & 84 & $94: 6$ & $94: 6$ \\
\hline 2 & $2 a$ & $3 b$ & $p-\mathrm{CH}_{3} \mathrm{OC}_{6} \mathrm{H}_{4}$ & $\mathrm{Me}$ & $4 b$ & 73 & $92: 8$ & $94: 6$ \\
\hline 3 & $2 a$ & $3 c$ & 5-Br-thiophen-2-yl & $\mathrm{Me}$ & $4 c$ & 78 & $88: 12$ & $93: 7$ \\
\hline 4 & $2 a$ & $3 d$ & $p-\mathrm{NO}_{2} \mathrm{C}_{6} \mathrm{H}_{4}$ & $\mathrm{Me}$ & $4 d$ & 60 & $90: 10$ & $95: 5$ \\
\hline 5 & $2 a$ & $3 e$ & $p-\mathrm{BrC}_{6} \mathrm{H}_{4}$ & $\mathrm{Me}$ & $4 \mathrm{e}$ & 71 & $89: 11$ & $95: 5$ \\
\hline 6 & $2 \mathrm{a}$ & $3 f$ & $p-\mathrm{CNC}_{6} \mathrm{H}_{4}$ & $\mathrm{Me}$ & $4 \mathrm{f}$ & 80 & $90: 10$ & $96: 4$ \\
\hline 7 & $2 a$ & $3 \mathrm{~g}$ & $4-\mathrm{F}, 3-\mathrm{BrC}_{6} \mathrm{H}_{3}$ & $\mathrm{Me}$ & $4 \mathrm{~g}$ & 83 & $85: 15$ & $89: 11$ \\
\hline 8 & $2 a$ & $3 h$ & $3,5-\left(\mathrm{CF}_{3}\right)_{2} \mathrm{C}_{6} \mathrm{H}_{3}$ & $\mathrm{Me}$ & $4 \mathrm{~h}$ & 82 & $86: 14$ & $88: 12$ \\
\hline 9 & $2 a$ & $3 \mathbf{i}$ & 5-methylthiazol-2-yl & $\mathrm{Me}$ & $4 i$ & 55 & $91: 9$ & $93: 7$ \\
\hline 10 & $2 \mathrm{a}$ & $3 \mathbf{j}$ & pyrazin-2-yl & $\mathrm{Me}$ & $4 j$ & 75 & $91: 9$ & $91: 9$ \\
\hline 11 & $2 a$ & $3 k$ & $\mathrm{Ph}$ & Et & $4 k$ & 76 & $90: 10$ & $99: 1$ \\
\hline 12 & $2 a$ & 31 & $p-\mathrm{MeC}_{6} \mathrm{H}_{4}$ & Et & 41 & 81 & $91: 9$ & $98: 2$ \\
\hline 13 & $2 a$ & $3 m$ & $p-\mathrm{FC}_{6} \mathrm{H}_{4}$ & Et & $4 \mathrm{~m}$ & 83 & $88: 12$ & $99: 1$ \\
\hline 14 & $2 a$ & $3 n$ & $p-\mathrm{BrC}_{6} \mathrm{H}_{4}$ & Et & $4 n$ & 73 & $90: 10$ & $99: 1$ \\
\hline 15 & $2 a$ & 30 & $\mathrm{Ph}$ & $\operatorname{Pr}$ & 40 & 79 & $87: 13$ & $99: 1$ \\
\hline 16 & $2 a$ & $3 p$ & 2-thienyl & $\operatorname{Pr}$ & $4 p$ & 81 & $84: 16$ & $96: 4$ \\
\hline 17 & $2 a$ & $3 q$ & $\mathrm{Ph}$ & $\mathrm{CH}_{2} \mathrm{iPr}$ & $4 q$ & 75 & $96: 4$ & $97: 3$ \\
\hline 18 & $2 b$ & $3 \mathrm{k}$ & $\mathrm{Ph}$ & Et & $4 r$ & 81 & $90: 10$ & $99: 1$ \\
\hline 19 & $2 b$ & 31 & $p-\mathrm{MeC}_{6} \mathrm{H}_{4}$ & Et & $4 \mathrm{~s}$ & 82 & $91: 9$ & $98: 2$ \\
\hline 20 & $2 c$ & $3 k$ & $\mathrm{Ph}$ & Et & $4 t$ & 77 & $91: 9$ & $99: 1$ \\
\hline
\end{tabular}

[a] Combined yield of both diastereomers after flash column chromatography. [b] Determined by ${ }^{1} \mathrm{H}$ NMR analysis of the crude reaction mixture. [c] Determined by HPLC analysis on a chiral stationary phase. heterocycles, ${ }^{[13]}$ we subsequently explored the conversion of oxazolines $\mathbf{4}$ into the corresponding amino acid derivatives under different reaction conditions. The hydrolysis of oxazoline $4 \mathbf{e}$ using catalytic amounts of $\mathrm{HCl}$ afforded the corresponding $N$-formyl derivative $\mathbf{6}$ in quantitative yield (Scheme $3 \mathrm{a}$ ). Similarly, methanolysis of $\mathbf{4 e}$ led to the corresponding $\beta$-hydroxy- $\alpha$-amino acid tertbutyl ester 7 under mild conditions (Scheme $3 b$ ). These transformations highlight the ability of our method to afford protected serine derivatives with a doubly substituted $\beta$-position. Furthermore, treatment of 7 with thiophosgene under basic conditions furnished crystalline oxazolidinethione $\mathbf{8}$ (Scheme $3 \mathrm{c}) ;{ }^{[14]}$ its absolute and relative stereochemical configurations were determined by single-crystal Xray diffraction, and those of the other oxazolines $(4 a-4 v)$ were assigned by analogy.

Based on previous reports ${ }^{[\mathrm{b}, 15]}$ and on the known absolute stereochemical configuration of oxazoline products $\mathbf{4}$, a transition-state model rationalizing the stereochemical outcome of the ketone aldol reaction between $\mathbf{3} \mathbf{a}$ and $\mathbf{2} \mathbf{a}$ in the presence of precatalyst $\mathbf{1 a}$ and silver oxide is proposed in Scheme 4. In the enantiodetermining carbon-carbon bond-forming step, the phosphorus and amide nitrogen atoms of $\mathbf{1} \mathbf{a}$, the oxygen atom of ketone $\mathbf{3 a}$, and the terminal carbon atom of the isonitrile coordinate to a silver(I) ion in a tetrahedral
As the stereochemical outcome favored the production of the trans-configured oxazoline product, and as alkyl groups larger than a methyl group were well tolerated in the ketone aldol reaction, our reaction could be applied to the synthesis of oxazoline-fused $\gamma$ - and $\delta$-lactam derivatives. Therefore, azides $3 \mathbf{r}$ and $\mathbf{3 s}$ were subjected to the standard reaction conditions, and pleasingly, oxazolines $4 \mathbf{u}$ and $4 \mathbf{v}$ were afforded in good yield and with excellent enantioselectivities. Subsequently, under standard Staudinger conditions, these oxazolines were transformed into the target lactam products 5a and 5b with high yields in a straightforward manner without compromising stereochemical integrity (Scheme 2).

To demonstrate further synthetic utility whilst expanding our knowledge on the hydrolytic manipulation of oxazoline

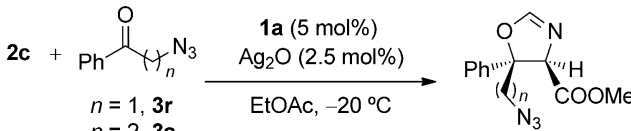

$$
\begin{aligned}
& \text { 4u } n=1,83 \%, 77: 23 \text { d.r., 98:2 e.r. } \\
& \text { 4v } n=2,79 \%, 76: 24 \text { d.r., 97:3 e.r. } \\
& \text { 1) } \frac{\mathrm{PPh}_{3}, \mathrm{THF}, \mathrm{RT}}{2} \\
& \text { 5a } n=1,83 \%, 98: 2 \text { e.r. } \\
& \text { 5b } n=2,73 \%, 97: 3 \text { e.r. }
\end{aligned}
$$

Scheme 2. Application of the ketone aldol reaction to the formation of fused bicyclic lactams. a)<smiles>CC(C)OC1N=COC1(C)c1ccc(Br)cc1</smiles><smiles>O=CNC(C(=O)OCc1ccc(Br)cc1)C(O)(O)c1ccccc1</smiles>

b)

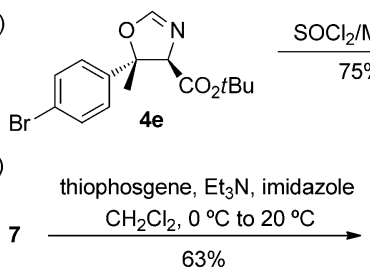<smiles>CC(O)(C(=O)O)C(N)C(=O)OCc1ccc(Br)cc1</smiles><smiles>CC(C)(C)OC1NC(=S)OC1(C)c1ccc(Br)cc1</smiles>

Scheme 3. Synthetic manipulations of the oxazoline products.

arrangement. Additional transition-state stabilization is provided through hydrogen bonding of the protonated quinuclidine to the coordinated ketone oxygen atom. Importantly, this interaction creates a well-defined chiral pocket that can readily differentiate the enantiotopic faces of the bound ketone; unfavorable steric interactions force the aryl group away from the quinuclidine, and attack of the enolate occurs preferentially to the $R e$ face.

In conclusion, we have developed the first highly enantioand diastereoselective aldol addition/cyclization reaction of isocyanoacetate esters with unactivated prochiral ketones to afford functionalized oxazolines with a fully substituted stereogenic center at the $\beta$-carbon atom. The reaction is 


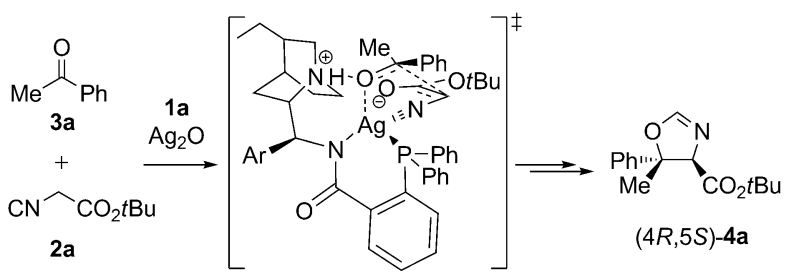

Scheme 4. Proposed transition-state model rationalizing the stereochemical outcome of the reaction of $\mathbf{3} \mathbf{a}$ and $\mathbf{2 a}$ in the presence of $\mathbf{1} \mathbf{a}$ and $\mathrm{Ag}_{2} \mathrm{O}$.

efficient and broad in scope and effectively promoted by a binary catalyst system that consists of a cinchona-derived aminophosphine precatalyst and silver oxide. In combination with hydrolytic transformations of the oxazoline heterocycles, this method enables the transformation of simple ketones into the corresponding amino acid derivatives possessing a tertiary alcohol in the $\beta$-position. Further studies towards the discovery and application of new asymmetric isocyanoacetate addition reactions are ongoing in our laboratories, and the results will be reported in due course.

Keywords: aldol reaction - asymmetric catalysis enantioselectivity $\cdot$ isocyanoacetates $\cdot$ oxazolines

How to cite: Angew. Chem. Int. Ed. 2015, 54, 4895-4898 Angew. Chem. 2015, 127, 4977-4980

[1] For reviews on asymmetric aldol reactions, see: a) R. Mahrwald in Modern Aldol Reactions, Wiley-VCH, Weinheim, 2004; b) B. M. Trost, C. S. Brindle, Chem. Soc. Rev. 2010, 39, 1600 1632; c) C. Palomo, M. Oiarbide, J. M. García, Chem. Soc. Rev. 2004, 33, 65-75; d) L. M. Geary, P. G. Hultin, Tetrahedron: Asymmetry 2009, 20, 131-173.

[2] a) K. C. Nicolaou, C. N. C. Boddy, S. Bräse, N. Winssinger, Angew. Chem. Int. Ed. 1999, 38, 2096-2152; Angew. Chem. 1999, 111, 2230-2287; b) M. K. Renner, Y. Shen, X. Cheng, P. R. Jensen, W. Frankmoelle, C. A. Kauffman, W. Fenical, E. Lobkovsky, J. Clardy, J. Am. Chem. Soc. 1999, 121, $11273-$ 11276 ; c) B. Herbert, I. H. Kim, K. L. Kirk, J. Org. Chem. 2001, 66, $4892-4897$.

[3] a) J. P. Guthrie, J. Am. Chem. Soc. 1991, 113, 7249-7255; b) M. Hatano, E. Takagi, K. Ishihara, Org. Lett. 2007, 9, 4527-4530.

[4] For examples of Lewis base catalysis, see: a) S. E. Denmark, Y. Fan, J. Am. Chem. Soc. 2002, 124, 4233-4235; b) S. E. Denmark, Y. Fan, M. D. Eastgate, J. Org. Chem. 2005, 70, 5235-5248; for reactions with enol silanes, see: c) K. Oisaki, D. Zhao, M. Kanai, M. Shibasaki, J. Am. Chem. Soc. 2006, 128, 7164-7165; d) K. Oisaki, Y. Suto, M. Kanai, M. Shibasaki, J. Am. Chem. Soc. 2003, 125, 5644-5645; e) X. Moreau, B. Bazan-Tejada, J. Campagne, $J$. Am. Chem. Soc. 2005, 127, 7288-7289; for reductive aldol reactions, see: f) H. W. Laim, P. M. Joensuu, Org. Lett. 2005, 7, 4225-4228; g) J. Deschamp, O. Chuzel, J. Hannedouche, O. Riant, Angew. Chem. Int. Ed. 2006, 45, 1292-1297; Angew. Chem. 2006, 118, 1314-1319; see also: h) S. Adachi, T. Harada, Eur. J. Org. Chem. 2009, $3661-3671$.

[5] a) E. J. Corey, A. Guzman-Perez, Angew. Chem. Int. Ed. 1998 37, 388-401; Angew. Chem. 1998, 110, 402-415; b) O. Riant, J. Hannedouche, Org. Biomol. Chem. 2005, 5, 873-888; c) P. G. Cozzi, R. Hilgraf, N. Zimmermann, Eur. J. Org. Chem. 2007, 5969-5994; d) M. Shibasaki, M. Kanai, Chem. Rev. 2008, 108,
2853-2873; e) M. Hatano, K. Ishihara, Synthesis 2008, 1647 1675.

[6] For a review on isocyanoacetates, see: a) A. V. Gulevich, A. G. Zhdanko, R. V. A. Orru, V. G. Nenajdenko, Chem. Rev. 2010, 110, 5235-5331; see also: b) W. A. Böll, F. Gerhart, A. Nürrenbach, U. Schöllkopf, Angew. Chem. Int. Ed. Engl. 1970, 9, 458-459; Angew. Chem. 1970, 82, 482-483; c) Y. Ito, T. Matsuura, T. Saegusa, Tetrahedron Lett. 1985, 26, 5781-5784.

[7] For enantioselective reactions of aldehydes, see: a) Y. Ito, M. Sawamura, T. Hayashi, J. Am. Chem. Soc. 1986, 108, 6405-6406; b) Y. Ito, M. Sawamura, T. Hayashi, Tetrahedron Lett. 1987, 28, 6215-6218; c) S. D. Pastor, A. Togni, J. Am. Chem. Soc. 1989, 111, 2333-2334; d) T. Hayashi, Y. Uozumi, A. Yamzaki, M. Sawamura, H. Hamashima, Y. Ito, Tetrahedron Lett. 1991, 32, 2799-2802; e) T. Hayashi, M. Sawamura, Y. Ito, Tetrahedron 1992, 48, 1999-2012; f) V. A. Soloshonok, T. Hayashi, Tetrahedron Lett. 1994, 35, 2713-2716; g) V. A. Soloshonok, A. Kacharov, T. Hayashi, Tetrahedron 1996, 52, 245-254; h) J. M. Longmire, X. Zhang, Organometallics 1998, 17, 4374-4379; i) M. Sawamura, Y. Nakayama, T. Kato, Y. Ito, J. Org. Chem. 1995, 60, 1727-1732; j) S. Gosiewska, M. H. Veld, J. J. M. de Pater, P. C. A. Bruijnincx, M. Lutz, A. L. Spek, G. van Koten, R. J. M. K. Gebbink, Tetrahedron: Asymmetry 2006, 17, $674-$ 686; k) M. Xue, C. Guo, L. Gong, Synlett 2009, 2191-2197; 1) H. Y. Kim, K. Oh, Org. Lett. 2011, 13, 1306-1309; m) F. Sladojevich, A. Trabocchi, A. Guarna, D. J. Dixon, J. Am. Chem. Soc. 2011, 133, 1710-1713.

[8] For enantioselective reactions of aldimines, see: a) X. Zhou, Y. Lin, L. Dai, J. Sun, L. Xia, M. Tang, J. Org. Chem. 1999, 64, 1331-1334; b) X. Zhou, Y. Lin, L. Dai, Tetrahedron: Asymmetry 1999, 10, 855-862; c) J. Aydin, A. Ryden, K. J. Szabó, Tetrahedron: Asymmetry 2008, 19, 1867-1870; d) Z. Zhang, G. Lu, M. Chen, N. Lin, Y. Li, T. Hayashi, A. S. C. Chan, Tetrahedron: Asymmetry 2010, 21, 1715-1721; e) P. Shao, J. Liao, Y. A. Ho, Y. Zhao, Angew. Chem. Int. Ed. 2014, 53, 5435-5439; Angew. Chem. 2014, 126, 5539-5543.

[9] For enantioselective reactions of ketimines, see: a) I. Ortín, D. J. Dixon, Angew. Chem. Int. Ed. 2014, 53, 3462-3465; Angew. Chem. 2014, 126, 3530-3533; b) M. Hayashi, M. Iwanaga, N. Shiomi, D. Nakane, H. Masuda, S. Nakamura, Angew. Chem. Int. Ed. 2014, 53, 8411-8415; Angew. Chem. 2014, 126, 8551-8555.

[10] For the racemic reaction, see: a) V. A. Soloshonok, A. D. Kacharov, D. V. Avilov, T. Hayashi, Tetrahedron Lett. 1996, 37, $7845-7848$; b) V. A. Soloshonok, A. D. Kacharov, D. V. Avilov, K. Ishikawa, N. Nagashima, T. Hayashi, J. Org. Chem. 1997, 62, $3470-3479$

[11] a) T. Yoshino, H. Morimoto, G. Lu, S. Matsunaga, M. Shibasaki, J. Am. Chem. Soc. 2009, 131, 17082-17083; b) S. Matsunaga, T. Yoshino, Chem. Rec. 2011, 11, 260-268.

[12] Experiments with pentan-3-one, propanone, and cyclohexyl methyl ketone gave oxazoline products $4 \mathbf{x}, 4 \mathbf{y}$, and $\mathbf{4 z}$ with enantiomeric ratios of 61:39, 47:53, and 67:33, respectively; see the Supporting Information for details.

[13] D. Hoppe, U. Schöllkopf, Angew. Chem. Int. Ed. Engl. 1972, 11, 432-433; Angew. Chem. 1972, 84, 435-436.

[14] CCDC 1036558 (8) contains the supplementary crystallographic data for this paper. These data can be obtained free of charge from The Cambridge Crystallographic Data Centre via www. ccdc.cam.ac.uk/data_request/cif.

[15] a) W. Zeng, G. Chen, Y. Zhou, Y. Li, J. Am. Chem. Soc. 2007, 129, 750-751; b) G. Liang, M. Tong, C. Wang, Adv. Synth. Catal. 2009, 351, 3101-3106; c) J. Song, C. Guo, P. Chen, J. Yu, S. Luo, L. Gong, Chem. Eur. J. 2011, 17, 7786-7790.

Received: December 9, 2014

Revised: January 23, 2015

Published online: March 3, 2015 